\title{
Knowledge Discovery based Framework for Enhancing the House of Quality
}

\author{
Amira M. Idrees ${ }^{1}$, Ahmed I. ElSeddawy ${ }^{2}$, Mohammed Ossama Zeidan ${ }^{3}$ \\ Information Systems Department, Faculty of Computers and Information, Fayoum University, Egypt ${ }^{1}$ \\ Arab Academy for Science, Technology and Maritime Transport, Egypt ${ }^{2}$ \\ Arab Academy for Science, Technology and Maritime Transport, Egypt ${ }^{3}$
}

\begin{abstract}
Mining techniques proved to have a successful impact in different fields for many targets; one of these targets is to gain customers' satisfaction through enhancing the products' quality according to the voice of these customers. This research proposes a framework that is based on mining techniques and adopted Saaty method targeting to gain the customers' satisfaction and consequently a competitive advantage in the real estate market. The proposed framework is applied during the design phase of a real estate residential building project as an improvement tool to design the building according to the customers' requirements representing the voice of customers (VOC). The proposed Saaty method adaptation increased the number of the consistent sample which was incorrectly excluded using the traditional Saaty method. Saaty method adaptation has succeeded in enhancing the house of quality (HOQ) by achieving the consistent technical customers' requirements for residential buildings, while customers' segmentation succeeded in focusing on the homogeneous grouping of customers.
\end{abstract}

Keywords-Knowledge discovery; mining techniques; customer segmentation; Saaty's method; customer satisfaction

\section{INTRODUCTION}

Customers' satisfaction is one of the continuous vital targets in business fields [1]. It is a fact that different researches have focused on customer satisfaction [2] either directly [3] or through other directions such as the process adaptation [4] [5] [6].

No doubt that VOC that represents the customers' requirements is a vital factor that should be considered by any service or product firm to compete in the market against competitors and consequently to have a competitive advantage. However, as customers have different personality, their preferences will naturally differ [7]. As mapping customers to residents is one of the keys for successful real estate business, therefore, identifying the suitable customer to each territory is one of the current research objectives. To achieve this target, these presented researches have highlighted a focus on the Quality Function Deployment (QFD) for enhancing the HOQ through considering the VOC.

Therefore, two perspectives should be considered for satisfying this variation and maintain the product quality as well. The first perspective is segmenting the customers according to their preferences, and the second perspective is to determine the consistency of these requirements. Different approaches have applied clustering mining techniques for segmenting the business customers [8] [9] [10], which consequently lead the firm to focus on the defined set of customers for achieving their need with ensuring their interestingness in the resident.

Focusing on the real state field, QFD achieved by focusing on the HOQ, the first phase of QFD, to integrate and analyze VOC before the design phase. QFD was first introduced in 1960s, it was used by several companies but did not draw much attention [11]. Few years later, QFD was implemented in Mitsubishi Heavy Industries, followed by Toyota Japan. Later QFD entered the US in General Motors, Chrysler, Digital Equipment, Hewlett-Packard, AT\&T, Procter and Gamble, and Baxter Healthcare.

This remaining of the research is as follows: section 2 represents the background describing QFD, HOQ, and advantage of using $\mathrm{HOQ}$, importance of design phase, competitive advantage, and customer satisfaction. Section 3 introduces the previous research which applied the traditional method in HOQ, as well as Saaty Model with highlighting the customer segmentation research in different fields in section 4. Section 5 proposes the customers' segmentation framework based on cluster mining technique and the Saaty method adaptation. Moreover, section 6 presents the case study, calculation, and final output results. Section 7 introduces customer evaluation on the proposed work before and after implementing the proposed HOQ approach. Finally, section 8 is the conclusion and the future work.

\section{House OF QuALiTy (HOQ)}

House of quality is the first phase of the QFD matrices, it is a subset of the QFD [12]. It is a diagram in a shape of a house with five walls [13] the left wall emphasizes the customer acquirements [14].

The focus of presented research is on the left walls which include the customers' requirements representing the VOC. This research enhances the left wall impact on the design phase by determining the consistent customers' requirements with focusing on their importance level. Consistent VOC is determined by the adopted Saaty method while the importance rate is determined through applying mining techniques.

\section{LITERATURE REVIEW FOR HOQ EVALUATION MODELS}

Decision Quality has been considered in many research for many fields such as in [15] [16]. Focusing on HOQ in residential field, Olewnik and Lewis (2008) discuss in their research that HOQ is a supportive tool for decision making 
which can be illustrated as a diagram with five walls where the left wall illustrates the VOC. Different methods are proposed for achieving the VOC, traditionally, a scale with a determined rate is used for the requirement evaluation [13]. Although the traditional method is widely used in a high range of applications and projects [14] [17], however, there results were obtained without excluding any customer sample which was a focus for many researchers due to its impact on the results' accuracy. Karsak and his colleagues in [11] used Saaty method in obtaining importance weighting in the HOQ, the results concluded that they were more accurate than the traditional method due to excluding the non-consistent customer samples in the HOQ calculations. Another research by Johny and Wong [18] which concluded that the examination of relationships was limited to those between the building system and selection criteria with the use of the AHP. Applying AHP (Saaty's method) for determining the consistency of the customers' evaluation can be illustrated in the following steps:

1) Matrix of requirements' comparison: Matrix of Requirements (MR) includes $\mathrm{N} * \mathrm{~N}$ items where $\mathrm{N}$ is the number of requirements. The matrix is built for each customer (MRcustomer i) which includes the relation between the requirements according to the customer preferred level, the preference varies from 1 representing the least preferred to 9 representing the most preferred. then:

Considering the preference of requirement $\mathrm{x}$ over $\mathrm{y}$ is $2 / 9$,

$\operatorname{MRx}, \mathrm{y}=2$ and $\mathrm{MR} y, \mathrm{x}=2 / 9=0.22$

2) Determine Eigen Vector matrix (EV): In this step, for each customer, Eigen vector is determined for each of his requirements as follows:

- Determine the product of each requirement preferences (Px) as follows:

$P_{x}=\prod_{y=1}^{n} M R_{x y}$

- Determine the total product for all requirements as follows:

$P_{\text {Total }}=\sum_{x=1}^{n} P_{x}$

- Eigen vector is determined by multiplying the preference value of each requirement over the other requirements divided by the summation of all products for all the requirements as follows:

Eigen vector $r_{x}=\frac{P_{x}}{P_{\text {Total }}}$

$\mathbf{E V}_{\text {Customer } i}=\left[\right.$ Eigen vector $\left.{ }_{i}\right]$ where $i=\{0,1,2, \ldots 10\}$

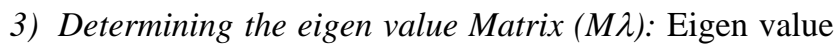
matrix is a one column matrix representing the value of $\lambda$ for each requirement, it is determined as follows:

$\mathbf{M} \lambda_{\text {Customer } i}=M R_{\text {Customer } i} \times \mathbf{E V}_{\text {Customer } i}$
4) Determining the Consistency Index (C.I): According to the traditional Saaty method, The consistency index (C.I) considers the maximum value of $\lambda(\lambda \max )$ for each customer $i$ that exists in $M \lambda_{\text {Customer } i}$ as follows:

C. $I_{\text {customer } i}=\left(\lambda_{\max }-n\right)(n-1)$

Where $\mathrm{n}$ is the number of requirements

5) Determining the Consistency Ratio (C.R): Finally, Consistency Ratio for customer i (C.R customer i) is calculated as follows:

$C R_{\text {customer } i}=C . I_{\text {customer } i} \times \frac{1}{m}$

Where $\mathrm{m}$ is a constant which value depends on the number of requirements [19].

\section{LIERATURE REVIEW FOR CUSTOMER SEGMENTATION BASED ON CLUSTERING MINING TECHNIQUES}

Traditionally, Customer segmentation is a significant method for providing a homogenous group while focusing on the customers' needs versus the market offers, however, customer segmentation can be performed by different criteria [20]. It could be based on their value, their lifetime value, or their customer need-based segmentation [21] [22]. Recently, firms are sharing the market in a critical environment in which it is a vital task to identify the customers' preferences and consequently determine the correct profitable decision [23]. Customers' segmentation supports driving the differentiation strategy as it is considered in this research a key for success for market initiative to customer/product matching.

In this direction, customer relationship management scope has been adopted to include the discrimination of customers' preferences. Including the customer life trend and assessing his current situation would be very efficient in predicting his preferences. Recently, data mining field has proved its effectiveness in the commercial field. Discovering interesting patterns such as correlations between stakeholders [20], patterns [24] and others [8] [25], could be different targets to use commercially [26]. Therefore, applying mining techniques could be very efficient for this target with respect to the available data [6]. Mining field offers efficient techniques including k-mean, statistics, neural networks, and others [27] [28]. Conducting the segmentation process through customers' behavioral approach especially in residential market can clearly illustrate the tacit market.

Customers' segmentation is considered an effective step [6] [9] [29], yet, selecting the suitable method for segmentation is also a target that should be focused on in order to reach a satisfying result [3] [21] [30]. Traditionally, mathematical methods are applied, however, it could not consider the correlations and other relations between the entities [31]. According to many research such as in [23] [32] [33], a focus on the customer value is a vital key rather than the customers' homogenous rate [34] [35].

Different approaches have been proposed which apply data mining techniques for CRM. A research in [32] proposed an approach for customer segmentation focusing on the customer behaviors while another research in [36] proposed a prediction 
model to predict the return of investment for the retention activities. While decision tree is one of the applied techniques as in [37], however, it is crucial as many decision could be a choice as the decision tree can provide too many instances as well as its large computation time which is one of the drawbacks in another mining technique named Neural Network $(\mathrm{NN})$. While k-means is one of the traditional approaches for clustering [38], however, it also has a considerable drawbacks. In this research follows applying the enhanced k-means algorithm that is proposed in [10] which overcome the traditional k-means drawbacks and provide other advantages in the computation as well as the output trustiness.

\section{Proposed Customer Segmentation Framework BASED ON ADOPTING SAATY METHOD}

Implementing data in the HOQ from customer samples was filtered to consider the consistent samples only. This was achieved by implementing Saaty method in all customers, the customer that turn consistent, their results have been implemented in HOQ. In this research, an adaptation has been recommended to Saaty method to gain better results, this adaptation has been applied and proved to gain more accurate results for the HOQ.

The results obtained from the HOQ, depend on the priorities of the customers' requirements and their preferences of these requirements as well as their value in the firm. These results considered in the design phase of the building. Implementing VOC in the residential designs leads the firm to gain a leading position in the market by surpassing customer expectations.

\section{Key STEPS IN THE PROPOSED FrAMEWORK}

The proposed framework includes two main key steps for reaching the required target. They are successful customer segmentation and applying the adopted Saaty method on the customers' data.

\section{APPLY KNOWLEDGE DISCOVERY FOR CUSTOMER SEGMENTATION}

Earlier, K-means algorithm has been applied for successful segmentation, however, different enhancements have been proposed for higher accuracy. A research in [10] proved an enhancement by changing the centroid point from random point to the center point. More research in applied k-means approach by using median calculation, or metoid calculation. Each of the previously mentioned research has proved the accuracy enhancement.

This research follows the enhancement in k-means which is applied in [10] with integrating the enhancement approach. The main enhancements in [10] is to adopt the random selected point to the centroid point. This enhancement has proved to achieve more accurate clustering results, the enhancement included to minimize the computation complexity by determining a suitable threshold and assign the element to its first matching class according to the determined threshold. This approach has proved its effectiveness in the biomedical field. As it was one of the future research to investigate new fields, therefore, in this research, we aim to prove its applicability in a different field which is the residential market. The following is the adopted formalization for enhanced k-means algorithm steps which is applied for for customers' segmentation phase

- Determine the set of clusters $S=\left\{S_{1}, S_{2}, \ldots . S_{i}\right\}$ where I is the number of clusters

- Determine the corresponding set of center points $\mathrm{C}\left\{\mathrm{C}_{1}\right.$, $\mathrm{C}_{2}, \ldots . \mathrm{C}_{\mathrm{i}}$ \}

- Repeat

- Determine the distance set Dij of data point $\mathrm{j}$ and the centers of all the clusters

- Determine the minimum element in Dij between the data point $\mathrm{j}$ and the centers of the clusters $\mathrm{i}$

- Determine the new mean for all clusters i

- Until no elements requires testing

\section{A. Adopting Saaty's Method}

Calculation of C.I using Saaty's method by using the maximum value of $\lambda$ from all $\lambda$ values turned to be that $\lambda$ max could be an extreme value and the other $\lambda$ 's are in range this will result that C.R will turn to be inconsistent due to that we have one extreme value and the other $\lambda$ 's that are in range if used to calculate C.R the result might turn to be consistent. This extreme value will cause decisions taken to refuse samples in calculations due to the inconsistency. This extreme value will lead to inaccurate decisions to exclude vital samples.

The proposed enhancement for Saaty's method is including other $\lambda$ calculations to $\lambda$ max, they are $\lambda$ mean and $\lambda$ median. Therefore the sample is decided to be consistent and is used in calculations of eigenvector and is used in the importance weight of HOQ if it had at least two of the three $\lambda$ measures to be $<0.4$. This approach in calculating three $\lambda$ measures is performed to avoid issues with extreme values.

To obtain correct data in the calculation obtaining appropriate numbers or $\lambda$ 's is mandatory. Obtaining appropriate data is reached by measuring the central tendency of the numbers $(\lambda)$. Central tendency is a numeric value that measures the middle value of data set and the spreading data around it. Central tendency is performed by measuring the mean, median, and mode, each of these measures is calculated differently, and the measure that is used best, depends upon the situation. This approach has been considered in this research by including mean and median in measuring $\lambda$. Mode measure is the value that appears most frequently or is repeated several times, therefore mode measure was not applicable in this research due to that it is hard to obtain repetitive numbers.

\section{PROPOSED FRAMEWORK ILLUSTRATION}

Fig. 1 illustrates the proposed framework phase which reveals the main applied steps to reach the required target. Section 6 presents the experimental study in which each step is discussed and applied in details. 


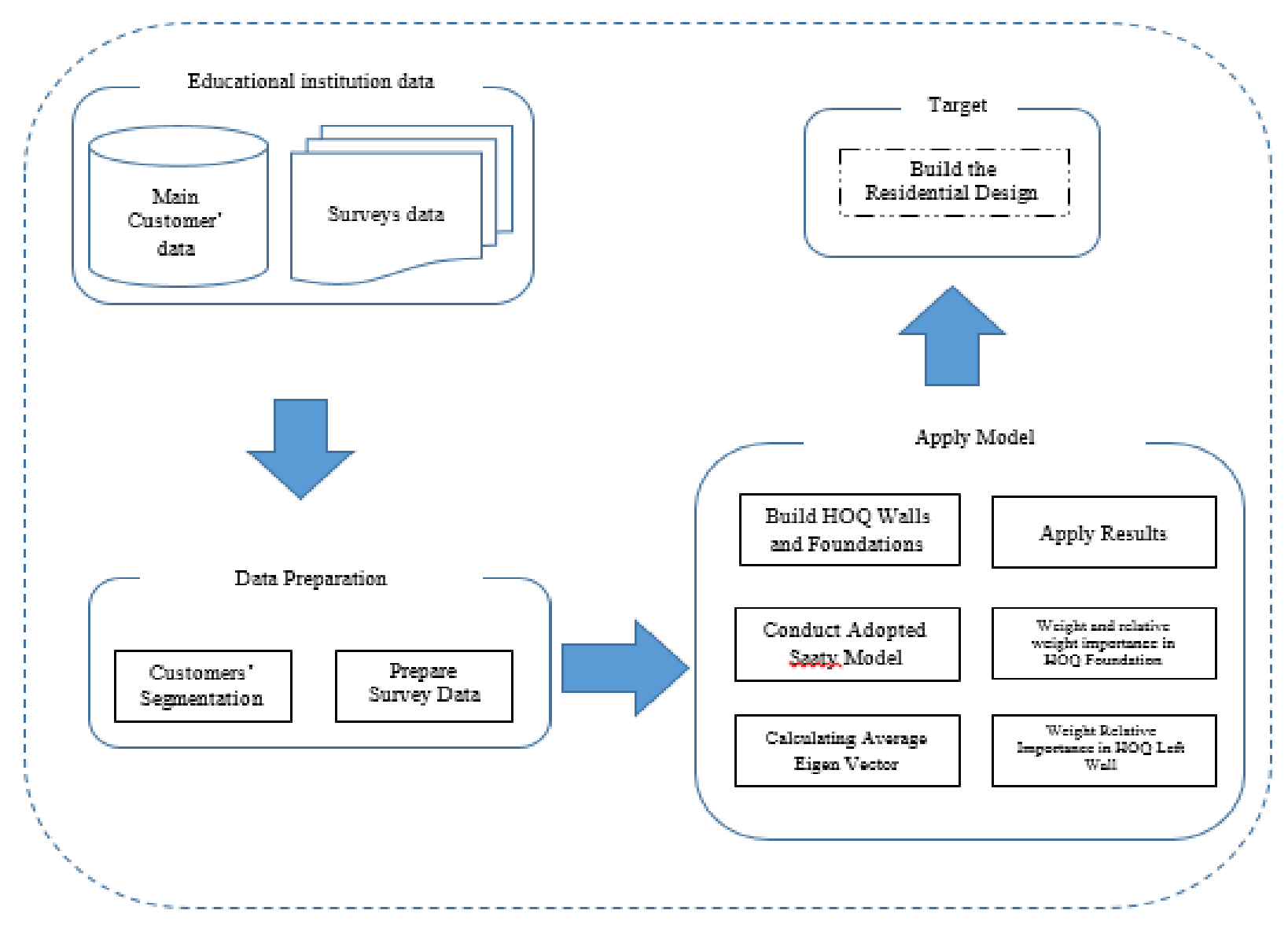

Fig. 1. Knowledge Discovery Based-Proposed Framework.

\section{EXPERIMENTAL STUDY}

Most of the research apply the experimental results using a bench mark dataset such as in [39] and [40], others used a real dataset such as in [41], [42] and [43].

One of the main strength factors in this research that the proposed framework has been applied on a real case. The proposed framework has been considered before design phase on residential buildings using the proposed adaptation of Saaty method. The experiment was performed on 'Abyat' which is one of the real state firms in the residential Egyptian market. The firm is located in the capital city of Cairo, in the province of Mokattam. The firm's targets the B- to B+ customer segment which are the medium value customers that represent around $40 \%$ of the market.

The target of customers' segmentation is to focus on a determined segment targeting to develop a real residential to this selected customers. Selecting a determined customers' segment is a positive step towards consistent requirements which is a positive support to the proposed Saaty method enhancement to ensure effective results.

Abyat Company targeted to build nine buildings in Mokattam area. The aim was to select from eight to fourteen customers of its customers' pool, apply the research phases on these customers' data and requirements, and then build the residential design according to these requirements. The experiment went all through the phases starting from selecting the customers, build the residential design, and build the residential according to the results performed from this research. Furthermore, a review has been developed to gather the customers' response and the results of this review is presented in this study. The study presents the old residential design and new design according to the recommendations of this research. Then the study presents the approval of the Egyptian government for the residential building and photos for the residential in its final implementation stage.

\section{CUSTOMERs' Segmentation AND Requirements' DETERMINATION}

Collecting customers' requirements were performed by interviewing sales persons who have direct contacts with customers to collect the required customers' data. According to the sales persons, the customers' requirements have been determined which is required as a preparatory step for the customers' segmentation. The experiment collected data for 120 customers, then Enhanced k-means algorithm is then applied. According to the limited number of customers that were required for the experiment, a segment with ten customers was selected [44]. Other segments included either more than 14 customers or less than eight customers which were out of the research limitation. Table 1 presents the internal and external requirements that are collected from the customers' segments. 
TABLE. I. VOC REQUIREMENTS FOR RESIDENTIAL BUILDINGS

\begin{tabular}{|l|l|l|}
\hline \multirow{4}{*}{$\begin{array}{l}\text { Internal } \\
\text { Requirements }\end{array}$} & 1. & Bathroom in master bed room \\
\cline { 2 - 3 } & 2. & Large kitchen that fits all appliances \\
\cline { 2 - 3 } & 3. & $\begin{array}{l}\text { Two extra rooms, so total of rooms would be } \\
\text { three rooms }\end{array}$ \\
\cline { 2 - 3 } & 4. & $\begin{array}{l}\text { Reception area fits more than two units } \\
\text { (minimum two) }\end{array}$ \\
\cline { 2 - 3 } & 5. & Large bathroom for whole family use \\
\cline { 2 - 3 } & 6. & $\begin{array}{l}\text { Apartment on front view elevation not back or } \\
\text { side view elevation }\end{array}$ \\
\hline \multirow{4}{*}{$\begin{array}{l}\text { External } \\
\text { Requirements }\end{array}$} & 7. & Elevator \\
\cline { 2 - 3 } & 8. & Attractive entrance appearance \\
\cline { 2 - 3 } & 9. & Attractive elevation appearance \\
\cline { 2 - 3 } & 10. & Garage for cars \\
\hline
\end{tabular}

\section{Apply Adaptive SaAty Method and BuILD the HOUSE OF QUALITY (HOQ)}

In this process the HOQ was implemented with the data that has been collected, the left wall of the HOQ is the VOC, the upper part of HOQ is the technical specifications that represent the needs of customer but in technical specification made by experts. In this step the implementation of data in the HOQ left wall, right wall, roof top, middle house, and foundation, without the weight of importance in the left wall which will be calculated using the proposed improvement of Saaty method.

The following is a sample of applying the proposed adaptation on one of the customers' data (Customer 1). Table 2 presents MRcustomer I while table 3 illustrates the values of $\mathrm{P}$ and Eigen vector for customer I preferences. Table 4 illustrates the $\mathrm{M} \lambda$, Moreover, table 5 presents C.I and C.R for customer 1 to determine the consistency of his preferences.

According to table 5, the requirements of customer 1 is consistent, due to that two of the $\lambda$ 's turn to be consistent, this sample customer data will be taken in the calculation of the HOQ. According to the Customers' requirements, Saaty's matrix is determined for each customer. Table 6 presents a sample of Saaty's matrix for 3 customers as an example including $\lambda$ max, $\lambda$ median, and $\lambda$ mean. The table data shows that depending on $\lambda$ max only will lead to inaccurate decision considering the requirements consistency while considering the three measures leads to including customers in a more stable approach. Using three different eigenvalues $(\lambda)$ three C.R were calculated for each of the ten customer, due to the three different values of $\lambda$, as described before in the improvement of Saaty's method, the samples that were accepted to be consistent is the samples with at least two of three consistent C.R's, in this case only four sample (sample 1,2,4 and 7) turn to be consistent, and these are the samples that will be taken in all calculations.

TABLE. II. MR FOR CUSTOMER 1

\begin{tabular}{|l|l|l|l|l|l|l|l|l|l|l|}
\hline & 1 & 2 & 3 & 4 & 5 & 6 & 7 & 8 & 9 \\
\hline 1 & 1.00 & 0.20 & 0.11 & 0.14 & 0.14 & 0.11 & 0.33 & 0.11 & 0.11 \\
\hline 2 & 5.00 & 1.00 & 0.20 & 0.14 & 3.00 & 0.11 & 3.00 & 0.14 & 0.14 \\
\hline 3 & 9.00 & 5.00 & 1.00 & 0.20 & 5.00 & 0.11 & 5.00 & 0.33 & 0.33 \\
\hline 4 & 7.00 & 7.00 & 5.00 & 1.00 & 0.14 & 0.11 & 5.00 & 0.33 & 0.33 \\
\hline 5 & 7.00 & 0.33 & 0.20 & 7.00 & 1.00 & 0.11 & 0.33 & 0.14 & 0.14 \\
\hline 6 & 9.00 & 9.00 & 9.00 & 9.00 & 9.00 & 1.00 & 9.00 & 9.00 & 9.00 \\
\hline 7 & 3.00 & 0.33 & 0.20 & 0.20 & 3.00 & 0.11 & 1.00 & 0.20 & 0.20 \\
\hline 8 & 9.00 & 7.00 & 3.00 & 3.00 & 7.00 & 0.11 & 5.00 & 1.00 & 7.00 \\
\hline 9 & 9.00 & 7.00 & 3.00 & 3.00 & 7.00 & 0.11 & 5.00 & 3.00 & 0.33 & 7.00 \\
\hline 10 & 0.20 & 0.14 & 0.11 & 0.14 & 0.14 & 0.11 & 0.14 & 0.14 & 0.14 \\
\hline
\end{tabular}

TABLE. III. CALCULATION OF EIGEN VECTOR FOR CUSTOMER 1

\begin{tabular}{|l|l|l|l|l|l|l|l|l|l|l|l|l|}
\hline & 1 & 2 & 3 & 4 & 5 & 6 & 7 & 8 & 9 & 10 & Product & Eigen Vector \\
\hline 1 & 1.00 & 0.20 & 0.11 & 0.14 & 0.14 & 0.11 & 0.33 & 0.11 & 0.11 & 5.00 & 0.25 \\
\hline 2 & 5.00 & 1.00 & 0.20 & 0.14 & 3.00 & 0.11 & 3.00 & 0.14 & 0.14 & 7.00 & 0.68 & 0.01 \\
\hline 3 & 9.00 & 5.00 & 1.00 & 0.20 & 5.00 & 0.11 & 5.00 & 0.33 & 0.33 & 9.00 & 1.38 & 0.04 \\
\hline 4 & 7.00 & 7.00 & 5.00 & 1.00 & 0.14 & 0.11 & 5.00 & 0.33 & 0.33 & 7.00 & 1.31 & 0.08 \\
\hline 5 & 7.00 & 0.33 & 0.20 & 7.00 & 1.00 & 0.11 & 0.33 & 0.14 & 0.14 & 7.00 & 0.67 & 0.04 \\
\hline 6 & 9.00 & 9.00 & 9.00 & 9.00 & 9.00 & 1.00 & 9.00 & 9.00 & 9.00 & 9.00 & 7.22 & 0.41 \\
\hline 7 & 3.00 & 0.33 & 0.20 & 0.20 & 3.00 & 0.11 & 1.00 & 0.20 & 0.20 & 7.00 & 0.57 & 0.03 \\
\hline 8 & 9.00 & 7.00 & 3.00 & 3.00 & 7.00 & 0.11 & 5.00 & 1.00 & 0.33 & 7.00 & 2.35 \\
\hline 9 & 9.00 & 7.00 & 3.00 & 3.00 & 7.00 & 0.11 & 5.00 & 3.00 & 1.00 & 7.00 & 2.93 & 0.13 \\
\hline 10 & 0.20 & 0.14 & 0.11 & 0.14 & 0.14 & 0.11 & 0.14 & 0.14 & 0.14 & 1.00 & 0.17 \\
\hline & & & & & & & & & & & 17.53 \\
\hline
\end{tabular}


TABLE. IV. CUSTOMER $1 \lambda$ VALUES

\begin{tabular}{|l|l|l|}
\hline \multirow{4}{*}{} & 1. & 12.92 \\
\cline { 2 - 3 } & 2. & 13.09 \\
\hline \multirow{4}{*}{} & 3. & 12.75 \\
\hline \multirow{4}{*}{4.} & 16.33 \\
\hline & 5. & 22.60 \\
\hline & 6. & 13.84 \\
\hline & 7. & 12.50 \\
\hline \multirow{2}{*}{ Total } & 8. & 11.89 \\
\hline & 9. & 11.81 \\
\hline & 10. & 14.02 \\
\hline
\end{tabular}

TABLE. V. CONSISTENCY OF CUSTOMER 1

\begin{tabular}{|l|l|l|l|l|}
\hline \multirow{4}{*}{ Customer 1 } & & $\lambda \max$ & $\lambda$ mean & $\lambda$ median \\
\cline { 2 - 5 } & $\lambda$ & 22.6 & 14.17 & 13.01 \\
\cline { 2 - 5 } & C.I & 1.4 & 0.46 & 0.33 \\
\cline { 2 - 5 } & C.R & 0.94 & 0.31 & 0.22 \\
\cline { 2 - 5 } & Consistency & Non-Const. & Const. & Const. \\
\hline
\end{tabular}

TABLE. VI. CONSISTENCY OF 3 Customers' SAMPLE WITH THREE $\lambda$ RESULTS

\begin{tabular}{|c|c|c|c|c|c|}
\hline & & $\lambda \max$ & $\lambda$ mean & $\lambda$ median & Decision \\
\hline \multirow{4}{*}{$\begin{array}{l}\text { Customer } \\
1\end{array}$} & $\lambda$ & 22.6 & 14.17 & 13.01 & \multirow{4}{*}{ Consistent } \\
\hline & C.I & 1.4 & 0.46 & 0.33 & \\
\hline & C.R & 0.94 & 0.31 & 0.22 & \\
\hline & Consistency & $\begin{array}{l}\text { Not- } \\
\text { Const. }\end{array}$ & Const. & Const. & \\
\hline \multirow{4}{*}{$\begin{array}{l}\text { Customer } \\
2\end{array}$} & $\lambda$ & 16.09 & 14.11 & 14.3 & \multirow{5}{*}{ Consisten } \\
\hline & C.I & 0.68 & 0.46 & 0.48 & \\
\hline & C.R & 0.45 & 0.31 & 0.32 & \\
\hline & Consistency & $\begin{array}{l}\text { Not- } \\
\text { Const. }\end{array}$ & Const. & Const. & \\
\hline \multirow{4}{*}{$\begin{array}{l}\text { Customer } \\
\mathbf{3}\end{array}$} & $\lambda$ & 22.88 & 15.89 & 14.69 & \\
\hline & C.I & 1.43 & 0.65 & 0.52 & \multirow{3}{*}{$\begin{array}{l}\text { Not } \\
\text { Consistent }\end{array}$} \\
\hline & C.R & 0.96 & 0.44 & 0.35 & \\
\hline & Consistency & $\begin{array}{l}\text { Not- } \\
\text { Const. }\end{array}$ & $\begin{array}{l}\text { Not- } \\
\text { Const. }\end{array}$ & Const. & \\
\hline
\end{tabular}

A new average matrix is formed from a ten consistent samples set, by obtaining the average matrix with the calculation of the eigenvector and implements the left wall of the HOQ in the weight importance column and therefore continuing the HOQ calculations. The importance weight in the HOQ foundation identifies the most important technical feature to the least important. Importance weight in the foundation is calculated by taking every technical column multiplying first need by the relative correlation in the row and adding the next requirement after multiplying it by its relative correlation.

For example, the importance weight of the third technical requirement apartment area between 110 and 150 is calculated as follows.

Weight importance $=[(0.1 * 9)+(0.1 * 9)+(0.2 * 9)+(0.1 * 9)$ $+(0.1 * 9)+(0.2 * 1)] * 100=487.6$

Relative weight is calculated by dividing importance weight by the total importance weight and multiplying it by 100 as follows:

Relative Weight $=\left(\frac{487.6}{48+77.3+487.6+156.5+113.8+60.4+67.3+31.8}\right) *$
$100=46.8 \%$

\section{APPLY RESULTS}

The final result obtained is shown in fig 3 while table 7 shows the ranking of the most important technical specifications that the design team needs to follow.

According to the experiment results, the residential design has been changed from fig. 2, fig. 3 and fig. 4 according to the technical requirements updates.

\section{TABLE. VII. RANKING OF TECHNICAL SPECIFICATIONS}

\begin{tabular}{|l|l|l|}
\hline & Technical Specification & \% Importance \\
\hline 1 & Apartment area between $110 \mathrm{~m}$ to $150 \mathrm{~m}$ & 46.8 \\
\hline 2 & Apartment rotation at main elevation view & 15.0 \\
\hline 3 & Elevators stop at all floors from garage to roof & 10.9 \\
\hline 4 & Increase are of kitchen to fit all appliances & 7.4 \\
\hline 5 & Modern style elevations and cheerful colors & 6.5 \\
\hline 6 & Marble and decoration in entrance of building & 5.8 \\
\hline 7 & Increase area of master room to fit bathroom & 4.6 \\
\hline 8 & Identify for each car a specific place in garage & 3 \\
\hline
\end{tabular}

\section{Evaluation}

After applying the results from HOQ, a survey has been applied to measure the customer satisfaction after the design updates. The customers were asked to give their feedback with a scale from 1 to 5 (where 1 is not satisfied and 5 is extremely satisfied) to compare their opinion for the first residential building design, with the new design that was obtained from the HOQ. The evaluation results are shown in table 8 which proves the higher satisfaction level using the new design. 


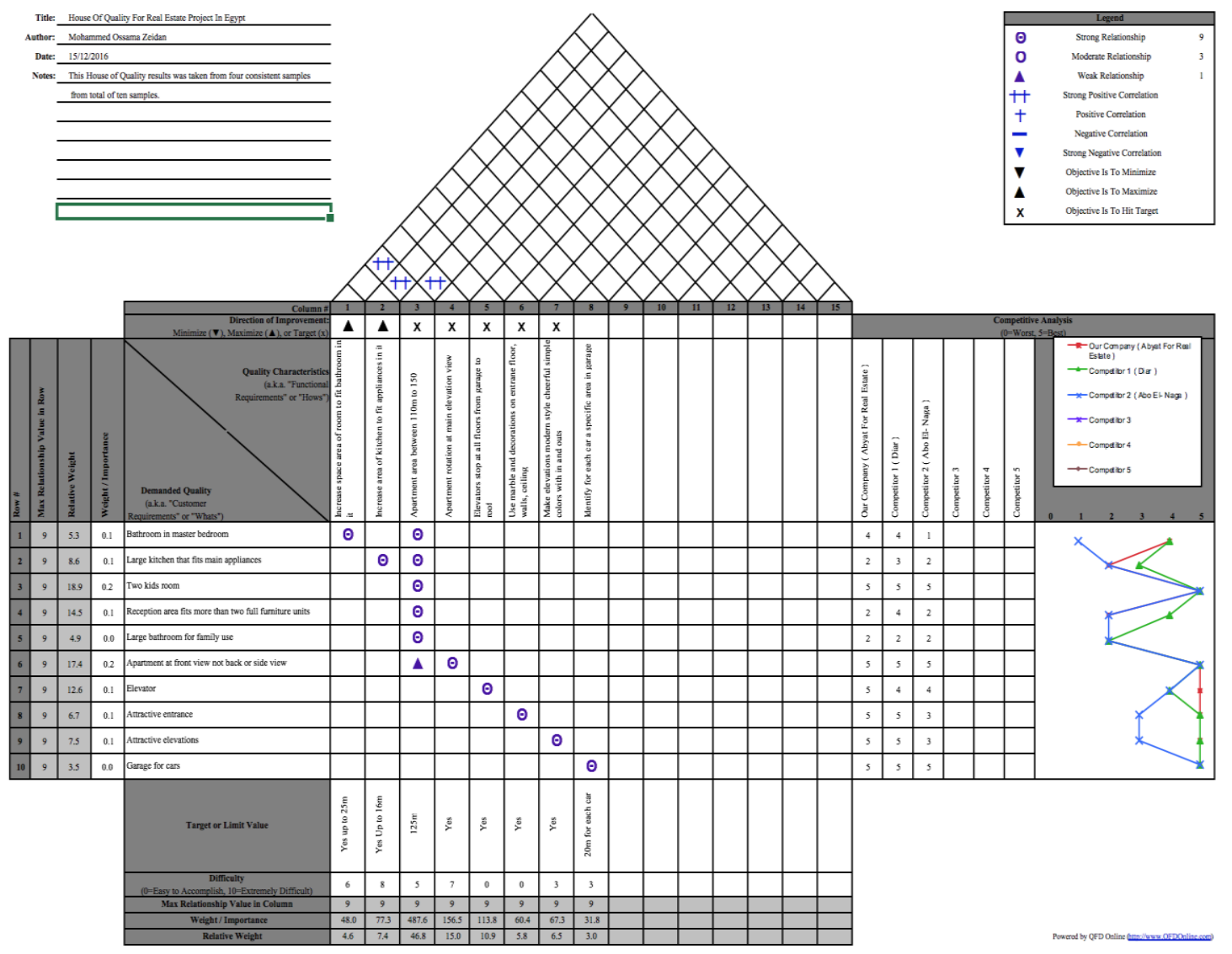

Fig. 2. House of Quality.

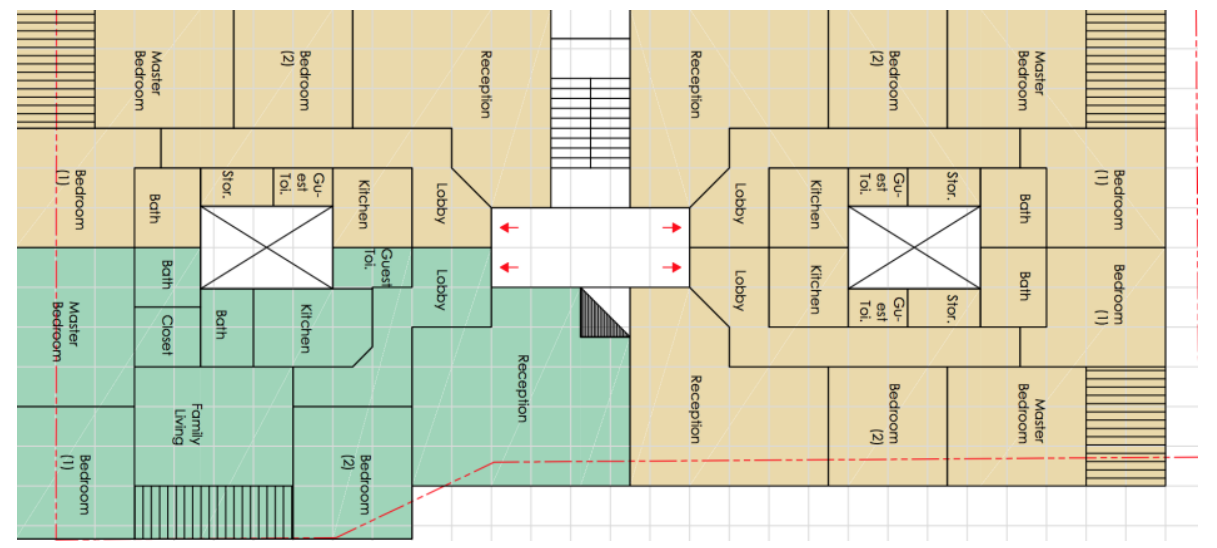

Fig. 3. Design of a Residential Apartment before House of Quality Results.

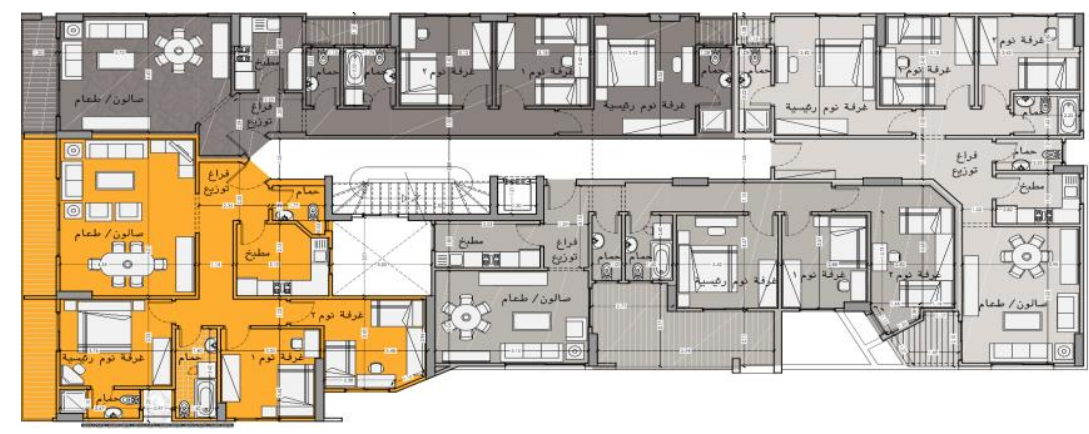

Fig. 4. Design of a Residential Apartment after Implementing House of Quality Result. 
TABLE. VIII. C CUSTOMER EVALUATION BEFORE AND AFTER HOQ

\begin{tabular}{|l|l|l|}
\hline Customer Needs & $\begin{array}{l}\text { Residential Building } \\
\text { Before VOC }\end{array}$ & $\begin{array}{l}\text { Residential Building } \\
\text { After VOC }\end{array}$ \\
\hline Bathroom in master bedroom & 3 & 5 \\
\hline Large kitchen that fits main appliances & 2 & 3 \\
\hline Two kids room & 3 & 5 \\
\hline Reception area fits more than two full furniture units & 3 & 3 \\
\hline Large bathroom for family use & 2 & 3 \\
\hline Apartment at front view not back or side view & 2 & 5 \\
\hline Elevator & 5 & 5 \\
\hline Attractive entrance & 4 & 4 \\
\hline Attractive elevations & 4 \\
\hline Garage for cars & 3 & 5 \\
\hline How Are You Satisfied with old and new design & \\
\hline
\end{tabular}

\section{RESEARCH SIGNIFICANCE}

Implementing the market with a product made by the VOC helped the organization turnover to become faster during the time period of the project. The main contribution in the research can be summarized in two main points: the successful customer segmentation which is performed by applying the enhanced k-means algorithm and the customer samples requirements consistency by considering three measures in the adaptive Saaty method which are $\lambda$ median, $\lambda$ max and $\lambda$ mean. According to the experiment results, applying customers' segmentation supported the proposed framework in gathering the most related customer in one resident, and including customers' requirements that could be previously excluded when using the traditional Saaty method.

\section{XV.CONCLUSION AND FUTURE RESEARCH}

House of quality is a valuable and flexible six sigma tool, as it was used on several products and services which was also very useful in real estate. House of quality helped the firm's architectural engineers to improve their design feature and specifications as per customer requirements, which leads the company to gain a competitive advantage in the market and customer's satisfaction. The importance of the results obtained from the house of quality ranked the important features of the customer from the most important to the least, which lead that the design was developed by the most important features the customer required to gain in his residential building.

The proposed approach has been applied and a real resident has been designed. The customers' satisfaction is measured using a survey which highlighted a higher satisfaction level with the new design. Currently, the resident is under construction in the real world in Mokattam area in Egypt.

The authors selected the residential field as information systems rarely applied in this field. Future directions is to confirm that the proposed approach is not limited to be applied in the residential field, the authors have a challenge in next research which is to prove the positive impact of the proposed approach on different fields. Another direction is investigating other data mining techniques to increase the approach accuracy. The authors also highlighted the necessity for the collaboration of different techniques which have different nature, one is heuristic approach and the other is a statistical approach.

\section{ACKNOWLEDGEMENT}

The authors would like to express their sincerest gratitude to Prof. Ayman E. Khedr who was leading all the research stages and provided insight and invaluably expertise that greatly assisted the research

\section{REFERENCES}

[1] Amira M. Idrees and Mohamed H. Ibrahim, "A Proposed Framework Targeting the Enhancement of Students' Performance in Fayoum University," International Journal of Scientific \& Engineering Research, vol. 9, no. 11, 2018.

[2] Ayman E. Khedr and Amira M. Idrees, "Adapting Load Balancing Techniques for Improving the Performance of e-Learning Educational Process," Journal of Computers, vol. 12, no. 3, pp. 250-257, 2017.

[3] Ayman E. Khedr and Ahmed I. El Seddawy, "A Proposed Data Mining Framework for Higher Education System," International Journal of Computer Applications, vol. 113, no. 7, pp. 24-31, 2015.

[4] Ayman E. Khedr and Amira M. Idrees, "Enhanced e-Learning System for e-Courses Based on Cloud Computing," Journal of Computers, vol. 12, no. 1, 2017.

[5] A. E. Khedr, S. A. Kholeif, and S. H. Hessen, "Adoption of cloud computing framework in higher education to enhance educational process," International Journal of Innovative Research in Computer Science and Technology (IJIRCST), vol. 3, no. 3, pp. Pp. 150 -156, March 2015.

[6] A. E. Khedr, S. A. Kholeif, and S. H. Hessen, "Enhanced Cloud Computing Framework to Improve the Educational Process in Higher Education: A case study of Helwan University in Egypt," International Journal of Computers \& Technology (IJCT), Volume 14, No. 6, pp. 5814 - 5823, April 2015.

[7] Ahmed Bahgat El Seddawy, Turky Sultan, and Ayman E. Khedr, "Enhanced K-mean Algorithm to Improve Decision Support System under Uncertain Situations," IJCSNS International Journal of Computer Science and Network Security, vol. 13, no. 7, 2013.

[8] Amr Mansour Mohsen, Hesham Ahmed Hassan, and Amira M. Idrees, "A Proposed Approach for Emotion Lexicon Enrichement," International Journal of Computer Electrical Automation Control and Information Engineering, vol. 10, no. 1, 2016.

[9] Amira M. Idrees and Mohamed Hassan, "A Proposed Framework Targeting the Enhancement of Students' Performance in Fayoum University," International Journal of Scientific \& Engineering Research, vol. 9, no. 11, 2018.

[10] Ayman E. Khedr, Ahmed I. El Seddawy, and Amira M. Idrees, "Performance Tuning of K-Mean Clustering Algorithm a Step towards Efficient DSS," International Journal of Innovative Research in Computer Science \& Technology (IJIRCST), vol. 2, no. 6, pp. 111-118, 2014.

[11] E.Ertugrul Karsak, Sevin Sozer, and S. Emre Aiptekin, "Product planning in QFD using a combined ANP and goal programming approach," Computers \& Industrial Engineering, vol. 44, pp. 171-190, 2002. 
[12] Elizabeth Cudney, C. Elrod Cassandra, and Anusha Uppalanchi, "Analyzing Customer Requirements for The American Society of Engineering Management Using Quality Function Deployment," Engineering Management Journal, vol. 24, no. 1, pp. 47-57, 2012.

[13] Luiz Antonio Gargione, "Using Quality Function Deployment (QFD) in The Design Phase of an Apartment Construction Project," University of California, California, 1999.

[14] Sukhlal Mujalda and Devendra Singh Verma, "Quality Function Deployment For Row House Construction In Real Estate," International Journal of Scientific \& Technology Research, vol. 4, no. 6, pp. 182-190, 2015.

[15] Ayman, E. Khedr, "Business Intelligence framework to support Chronic Liver Disease Treatment," International Journal of Computers \& Technology, vol. 4, no. 2, pp. 307-312, 2013.

[16] Mostafa Medhat Nazier, Ayman E. Khedr, and Mohamed Haggag, "Business Intelligence and its role to enhance Corporate Performance Management," International Journal of Management \& Information Technology, vol. 3, no. 3, 2013.

[17] Li Ma Wan and Jun Zhou Li, "Research on the Application of Quality Function Deployment Principles in Real Estate Development," in The CRIOCM 2006 International Symposium, Beijing, China, 2011.

[18] Wong K.W. Johnny and Li Heng, "Application of the analytic hierarchy process (AHP) in multi-criteria analysis of the selection of intelligent building systems," Building and Environment, vol. 43, no. 1, pp. 108125, 2008.

[19] David L. Olson, "The Analytic Hierarchy Process," in Decision Aids for Selection Problems.: Springer, New York, NY, 1996, pp. 49-68.

[20] Ayman E. Khedr, Amira M. Idrees, and Ahmed I. El Seddawy, "Enhancing Iterative Dichotomiser 3 algorithm for classification decision tree," WIREs Data Mining Knowledge Discovery, vol. 6, pp. 70-79, 2016.

[21] Ayman Khedr, Sherif Kholeif, and Fifi Saad, "An Integrated Business Intelligence Framework for Healthcare Analytics," International Journal of Advanced Research in Computer Science and Software Engineering, vol. 7, no. 5, pp. 263-270, 2017.

[22] Ayman E. Khedr, Amira M. Idrees, Abd El-Fatah Hegazy, and Samir ElShewy, "A proposed configurable approach for recommendation systems via data mining techniques," Enterprise Information Systems, vol. 12, no. 2, pp. 196-217, 2017.

[23] Bruce Cooil, Timothy L. Keiningham, Lerzan Aksoy, and Michael Hsu, "A Longitudinal Analysis of Customer Satisfaction and Share of Wallet: Investigating the Moderating Effect of Customer Characteristics," Journal of Marketing, vol. 71, no. 1, pp. 67-83, 2007.

[24] Mohamed Yehia Dahab, Amira Mohamed Idrees, Hesham Ahmed Hassan, and Ahmed Rafea, "Pattern Based Concept Extraction for Arabic Documents," The International Journal of Intelligent Computing and Information Sciences, vol. 10, no. 2, 2010.

[25] Amr Mansour Mohsen, Heshem Ahmed Hassan, and Amira M. Idrees, "Documents Emotions Classification Model Based on TF IDF Weighting," International Journal of Computer Electrical Automation Control and Information Engineering, vol. 10, no. 1, 2016.

[26] Ian H. Witten and Eibe Frank, Data Mining Practical Machine Learning Tools and Techniques.: Elsevier, 2005.

[27] Hesham Ahmed Hassan, Mohamed Yehia Dahab, Khaled Bahnassy, Amira M. Idrees, and Fatma Gamal, "Arabic Documents Classification Method a Step towards Efficient Documents Summarization," International Journal on Recent and Innovation Trends in Computing and Communication, vol. 3, no. 1, pp. 351-359, 2015.

[28] Mahmoud Othman, Hesham Hassan, Ramadan Moawad, and Amira M. Idrees, "A Linguistic Approach for Opinionated Documents Summary," Future Computing and Informatics Journal, vol. 3, no. 2, pp. 152-158, 2018.
[29] Manal A. Abdel-Fattah, Ayman E. Khedr, and Yasmine Nagm Aldeen, "An Evaluation Framework for Business Process Modeling Techniques," International Journal of Computer Science and Information Security (IJCSIS), vol. 15, no. 5, pp. 382-392, 2017.

[30] Aya M. Mostafa, Ayman E. Khedr, and A. Abdo, "Advising Approach to Enhance Students' Performance Level," Journal of Computer Sciences, vol. 13, no. 5, pp. 130-139, 2017.

[31] Orsay Kucukemiroglu, "Market segmentation by using consumer lifestyle dimensions and ethnocentrism: An empirical study," European Journal of Marketing, vol. 35, no. 5/6, pp. 470-487, 1999.

[32] Sankar Rajagopal, "Customer Data Clustering Using Data Mining Technique," International Journal of Database Management Systems ( IJDMS ), vol. 3, no. 4, pp. 1-11, 2011.

[33] Mahmoud Mohammadian and Iman Makhani, "RFM-Based customer segmentation as an elaborative analytical tool for enriching the creation of sales and trade marketing strategies," International Academic Journal of Accounting and Financial Management, vol. 3, no. 6, pp. 21-35, 2016.

[34] Hyun Gon Kim and Zhan Wang, "Defining and measuring social customer-relationship management (CRM) capabilities," Journal of Marketing Analytics, vol. 7, no. 1, pp. 40-50, 2019.

[35] Sarah Jane Flaherty, Mary B. McCarthy, Alan M. Collins, and Fionnuala M. McAuliffe, "A different perspective on consumer engagement: exploring the experience of using health apps to support healthier food purchasing," Journal of Marketing Management, vol. 35, no. 3/4, pp. 310-337, 2018.

[36] Scott A. Neslin, Sunil Gupta, Wagner Kamakura, Junxiang Lu, and Charlotte H Mason, "Defection Detection: Measuring and Understanding the Predictive Accuracy of Customer Churn Models," Journal of Marketing Research, vol. 43, no. 2, pp. 204-211, 2006.

[37] Giuliano Tirenni, Christian Kaiser, and Andreas Herrmann, "Applying decision trees for value-based customer relations management: Predicting airline customers' future values," Journal of Database Marketing \& Customer Strategy Management, vol. 14, no. 2, pp. 130142, 2007.

[38] Chinedu Pascal Ezenkwu, Simeon Ozuomba, and Constance Kalu, "Application of K-Means Algorithm for Efficient Customer Segmentation: A Strategy for Targeted Customer Services," International Journal of Advanced Research in Artificial Intelligence, vol. 4, no. 10, pp. 40-44, 2015.

[39] Ayman E. Khedr, "Towards Three Dimensional Analyses for Applying E-Learning Evaluation Model: The Case of E-Learning in Helwan University," IJCSI International Journal of Computer Science Issues, vol. 9, no. 4, pp. 161-166, 2012.

[40] Mahmoud Othman, Hesham Hassan, Ramadan Moawad, and Amira M. Idrees, "Using NLP Approach for Opinion Types Classifier," Journal of Computers, vol. 11, no. 5, pp. 400-410, 2016.

[41] Elsayed Azhary, Amira M. Idrees, and Ahmed Rafea, "Diagnostic expert system using non-monotonic reasoning," Expert Systems with Applications, vol. 23, no. 2, 2002.

[42] Maryam Hazman and Amira M. Idrees, "A Healthy Nutrition Expert System for Children," in The 5th IEEE International Conference on EHealth and Bioengineering - EHB 2015, 2015.

[43] Hesham Ahmed Hassan, Mohamed Yehia Dahab, Khaled Bahnasy, Amira M. Idrees, and Fatma Gamal, "Query answering approach based on document summarization," International Open Access Journal of Modern Engineering Research, vol. 4, no. 12, 2014.

[44] Hesham A. Hassan and Amira Mohamed Idrees, "Sampling Technique Selection Framework for Knowledge Discovery," in 7th International Conference on Informatics and Systems (INFOS), Cairo, 2010, pp. 1 - 8. 